\title{
Compromise or complement? Exploring the interactions between sustainable and resilient supply chain management
}

\section{Raphael Karutz}

Institute for Infrastructure and Resources Management, University of Leipzig,

Grimmaische Straße 12, 04109 Leipzig, Germany

Email: rk97gesu@studserv.uni-leipzig.de

\section{Lukas Riedner}

Institute for Business, Economics and Social Sciences, University of Graz,

Universitätsplatz 3, 8010 Graz, Austria

Email: lukas.riedner@edu.uni-graz.at

\section{Luisa Robles Vega and Lukas Stumpf}

Institute for Infrastructure and Resources Management, Environmental Technology/Environmental Management, University of Leipzig,

Grimmaische Straße 12, 04109 Leipzig, Germany

Email: luisa.robles@gmx.net

Email: 1s46hana@studserv.uni-leipzig.de

\section{Matthias Damert*}

Institute of Systems Sciences, Innovation and

Sustainability Research (SIS),

FWF-DK Climate Change,

University of Graz,

Brandhofgasse 5, 8010 Graz, Austria

Email: matthias.damert@uni-graz.at

*Corresponding author

\begin{abstract}
Supply chain management (SCM) increasingly needs to address both climate change mitigation and adaptation issues. While mitigation aims at sustainability by reducing the environmental impact of supply chains (SCs), adaptation entails improving resilience by increasing the ability to cope with climate-induced disruptions. Although sustainable SCM (SSCM) and resilient SCM (RSCM) are of increasing importance, there has been little effort to conceptually connect SSCM and RSCM. Our study explores the interconnections between both concepts by outlining theoretical elements and conducting a case study of four companies in the automotive SC based on company documents and interviews. Results show that SSCM is prioritised
\end{abstract}


over RSCM. We furthermore highlight trade-offs and overlaps between the elements of SSCM and RSCM, which can be valuable for decision-makers, and introduce two enabling factors: transparency and diversity. We present a novel theoretical SCM framework that integrates both resilience and sustainability perspectives and make propositions for future research.

Keywords: supply chain management; SCM; sustainability; resilience; climate change; mitigation; adaptation; automotive industry; case study; content analysis.

Reference to this paper should be made as follows: Karutz, R., Riedner, L., Robles Vega, L., Stumpf, L. and Damert, M. (2018) 'Compromise or complement? Exploring the interactions between sustainable and resilient supply chain management', Int. J. Supply Chain and Operations Resilience, Vol. 3, No. 2, pp.117-142.

Biographical notes: Raphael Karutz studied Renewable Energy Engineering BSc from the University of Stuttgart before enrolling in his current program, the Joint International Master in Sustainable Development from the Universities of Leipzig and Graz. In parallel, he works as a Research Assistant at the Helmholtz Centre for Environmental Research in Leipzig (Germany) in the field of urban transformations towards sustainability and resilience. His interests include the nexus between technology and socio-ecological transformations where he has already gained practical insights by doing internships in the fields of renewable energy project development and stakeholder involvement. For his master thesis, he investigates the role that rooftops can play in the context of urban sustainability transformations.

Lukas Riedner holds two Master's in International Marketing as well as in Global Studies. In his master theses he dealt with the subject of how family businesses can be visualised in a dynamic way and how the use of electric vehicles is assessed by Styrian farmers. During his studies, he did an internship at a start up in Copenhagen and at the Austrian Economic Chamber in Bucharest and was involved in various market research projects. Currently, he works as a Business Analyst at NIELSEN in Vienna.

Luisa Robles Vega holds two Bachelor's in Business Administration and International Relations. After her studies, she worked for two leading multinational consumer goods companies. Subsequently, she was awarded a scholarship from the National Council for Science and Technology (CONACYT) and the Mexican Ministry of Energy (SENER) for the Joint International Master in Sustainable Development at the Universities of Leipzig and Graz. She gained practical knowledge on organizational responses to climate change during an internship at CDP Europe. Her Master's thesis deals with the interrelations between sustainable development goals (SDGs) on energy sustainability, climate change, and sustainable cities for the Mexican case.

Lukas Stumpf holds a Bachelor's in International Cultural Studies and Economics and is currently studying the Joint International Master in Sustainable Development in Leipzig, Germany. He is working as a Research Assistant at Leipzig University, dealing with circular economy and consultative life cycle assessments. Apart from that, his current research and professional interests are in the areas of supply chain management, sustainability issues in global supply chains, as well as drivers and barriers for supply chain innovation. He has already worked in supply chain management related activities in the cocoa as well as the apparel sector. 


\begin{abstract}
Matthias Damert is a Research Associate and $\mathrm{PhD}$ candidate from the University of Graz in Austria within the interdisciplinary doctoral program 'Climate Change - Thresholds, Uncertainties and Coping Strategies'. He holds a Joint Master's in Sustainable Development from the Universities of Leipzig, Graz and Venice and a BSc in Economics and Management from the University of Leipzig. He has gained relevant practical knowledge while working for the Fraunhofer Institute for Systems and Innovation Research in Karlsruhe (Germany) and the airport operator Fraport AG. His current research focuses on the determinants, characteristics and outcomes of organisational responses to climate change issues with a special focus on the global automotive industry and its supply chain. He has published papers in reputed international journals, presented his work at international conferences in the field and taught courses on sustainable supply chain management at university level.
\end{abstract}

\title{
1 Introduction
}

The Paris Agreement (UNFCCC, 2015) gives evidence of how climate change and its impacts are becoming of paramount importance in the international arena. As a result, various industries and their supply chains (SCs) are being challenged to transition towards more sustainable practices, both in terms of reducing environmental footprints and the need to adapt to climate impacts.

The automotive industry serves as a prominent example. While being highly competitive and dynamic, its products are resource and emission-intensive in both the production and use phases. In 2013, terrestrial transport alone accounted for $17 \%$ of global $\mathrm{CO}_{2}$ emissions from fossil fuel combustion, a number that has increased by $68 \%$ since 1990 (IEA, 2015). The results are social, economic and environmental pressures that pose challenges to the industry ( $\mathrm{PwC}, 2007)$. The globalised and complex nature of the industry's SC furthermore exacerbates the risks associated with the indirect (e.g., mitigation policies) and direct effects (e.g., extreme weather events) of climate change. Although stake and shareholders mainly call for action from original equipment manufacturers (OEMs) (PwC, 2007), suppliers account for up to $70 \%$ of the industry's value added (Di Botonto, 2014) and thus play a pivotal role for effectively responding to climate change issues.

To account for these changes in the business environment, researchers have broadened the scope of traditional supply chain management (SCM) concepts by adding aspects such as the relationships within and between companies related to logistic activities, risk management, performance assessment, and, more recently, sustainability and resilience (Christopher and Peck, 2004; Seuring and Müller, 2008; Colicchia and Strozzi, 2012; Hassini et al., 2012). In the context of climate change, the latter two concepts are of particular importance:

1 sustainability, as a response to demands for carbon emission reductions

2 resilience, as a response to climate adaptation issues.

SCM research has accounted for sustainability issues by integrating the triple bottom line (TBL) approach (ensuring economic prosperity, while minimising negative social and environmental impacts) into SCM, resulting in the concept of sustainable supply chain 
management (SSCM) (Seuring and Müller, 2008). A second line of argumentation revolves around the concept of resilience. Despite its origins in ecology (Holling, 1973), it is also applied to SCM, given that companies and their SCs are systems that not only exert but also absorb economic, social and environmental impacts. For this reason, characteristic elements of resilience theory have been used as a starting point to derive concepts for resilient supply chain management (RSCM) (Christopher and Peck, 2004; Ponomarov and Holcomb, 2009; Linnenluecke and Griffiths, 2012; Carvalho et al., 2014).

Despite the increasing relevance of SSCM and RSCM for coping with climate change issues, research has so far largely neglected the need for a systematic integration of the two concepts. To address this gap, Derissen et al. (2011) and Mari et al. (2014) use a theoretical socio-economic and a multi-objective optimisation model, respectively. Derissen et al. (2011, p.1127) mention that "the deduction from sustainability to resilience, or vice versa, is not possible.". Redman (2014) gives recommendations to direct future research based on current developments in resilience theory and sustainability science, concluding that "we must rigorously pursue adoption of distinct resilience and sustainability approaches, as well as combinations of the two, allowing each approach to contribute in ways that reflect its strengths." (p.37). Fahimnia and Jabbarzadeh (2016, p.309) note that "there are situations in which sustainability initiatives and practices can influence SC capacity in tackling unanticipated disruptions." None of these studies tries to narrow the gap between research and practice by complementing theoretical concepts with empirical information, hence practical applicability of the findings is limited. Motivated by this research gap, the present paper aims to

1 explore the interplay of SSCM and RSCM practices from both a conceptual and a practical perspective

2 derive propositions that can be of guidance for future research.

In contrast to the few existing studies on the interconnections between sustainability and resilience in SCM, we adopt an explorative and qualitative research approach that uses theoretical notions from the SCM literature to explore practical perspectives. Through a case study of companies in the automotive SC, we first integrate empirical information and opinions of practitioners to close the gap between theory and practice and second, extend existing conceptual frameworks on SSCM and RSCM by proposing a novel SCM framework that comprises both resilience and sustainability aspects. We focus on climate change as one of the most pressing environmental issues which calls for SCM responses in terms of both sustainability (climate change mitigation) and resilience (climate change adaptation). Because the automotive industry significantly contributes to climate change and is also vulnerable to its adverse effects due to a highly globalised and complex SC, we deem it a promising object of investigation for gaining insights into how the RSCM-SSCM nexus is dealt with in practice.

The remainder of the paper is structured as follows. In the next section, we discuss the theoretical background of SSCM and RSCM. To confront theory with practice, we subsequently present findings from a case study of suppliers in the automotive industry and derive a conceptual framework and propositions for further research. 


\section{Theoretical background: sustainability and resilience of supply chains}

\subsection{Sustainable supply chain management}

The making of a product often entails environmental and social burdens not only during the different manufacturing stages, but throughout its entire life-cycle. This is one of the reasons why the need to integrate the issue of sustainability in SC operations has been increasingly acknowledged (Seuring and Müller, 2008). Two prominent definitions for SSCM are the ones by Seuring and Müller (2008) and Carter and Rogers (2008). Both definitions are among the most comprehensive ones in the literature with regard to the number of proposed formative elements of SSCM they include. However, a more recent study by Ahi and Searcy (2013) broadens the perspective of the two above-mentioned definitions. As a result of an extensive comparative literature review, the authors also integrate notions from other studies on SSCM and green SCM and, as a result, define $\mathrm{SSCM}$ as
"The creation of coordinated SCs through the voluntary integration of economic, environmental, and social considerations with key inter- organizational business systems designed to efficiently and effectively manage the material, information, and capital flows associated with the procurement, production, and distribution of products or services in order to meet stakeholder requirements and improve the profitability, competitiveness, and resilience of the organization over the short and long-term." [Ahi and Searcy, (2013), p.339]

In this definition, Ahi and Searcy (2013) highlight several key characteristics of SSCM that stem from business sustainability (Dahlsrud, 2008) and SCM (Stock and Boyer, 2009) notions. First, there are five SSCM elements related to business sustainability: TBL focus, long-term perspective, resilience, voluntariness, and stakeholder orientation (Dahlsrud, 2008; Ahi and Searcy, 2013). A focus on the TBL approach of sustainability encompasses that a company opts for ensuring economic prosperity while minimising negative social and environmental impacts. A long-term perspective should be taken by a company due to the long-term nature of sustainability, e.g., through taking measures related to end-of-life (EoL) product management, product reuse, product recovery, or reverse logistics. Voluntariness describes the voluntary nature of business sustainability activities. Stakeholder orientation emphasises the need to engage with stakeholders, such as NGOs, legislators or local communities, to identify and meet their needs and requirements (Harrison et al., 2010). A notable characteristic of Ahi and Searcy's (2013) concept is the inclusion of resilience, which is otherwise only addressed in a definition by Closs et al. (2011). To our knowledge, it is thus one of the first holistic approaches, in the sense that it already integrates sustainability and resilience notions. Yet, resilience is still addressed relatively vaguely as the "ability to recover from or adjust easily to misfortune or change" (Ahi and Searcy, 2013). We argue that resilience is a much broader concept in a SCM context, and therefore, we will elaborate on the notion of RSCM in the following section in more detail.

As for SCM, Ahi and Searcy (2013) identify seven constituents that are in line with previous findings from Burgess et al. (2006) and Stock and Boyer (2009): flow management, coordination, relationships, value creation, efficiency, performance, and stakeholder orientation. Flow management encompasses the management of material, 
capital, services and information flows. Coordination is related to management activities and coordination efforts within the organisation and/or between organisations at different organisational levels and stages of the product life cycle. Relationships refer to the diverse networks of internal and external relationships, as well as to collaborations within a company and its SC. Value creation concerns an organisation's value creation processes, including profit and market share maximisation and the conversion of resources into products. Efficiency is closely linked to the reduction of inputs, such as time, money, materials, and other resources. Performance summarises performancerelated actions such as conducting performance assessments monitoring, improvements in performance and competitiveness, and the achievement of established goals. Lastly, stakeholder orientation is a shared characteristic with business sustainability.

When comparing Ahi and Searcy's proposed definition of SSCM with other popular definitions in the research field, such as the ones by Seuring and Müller (2008) and Carters and Rogers (2008), we argue that the former is the most inclusive one. Seuring and Müller's definition (2008) misses six important elements: voluntariness, resilience, the long-term perspective, value creation, efficiency and performance. Likewise, Carter and Rogers (2008) do not address voluntariness, resilience, flow management, value creation, and efficiency. Moreover, as one of a few studies on SSCM, Ahi and Searcy's (2013) definition refers to the importance of resilience and hence creates a link to RSCM. We therefore deem this definition as particularly suitable for the purpose of our study.

\subsection{Resilient supply chain management}

Interest in resilient SCs grew in the last years, reflected in a growing number of scientific articles (Christopher and Peck, 2004; Carvalho et al., 2014; Mensah and Merkuryev, 2014). This is due to increasing complexity and globalisation of SCs and higher disruption risks caused by environmental and human-induced events (Pettit et al., 2010; Sáenz and Revilla, 2014; Barroso et al., 2015). However, RSCM is still an emerging field and as such, it is highly dynamic with regard to its definition and formative elements (Carvalho et al., 2014; Kim et al., 2015).

Based on a definition by the ecologist Holling (1973), the concept of resilience has been extended over the years and applied in several other fields of research. Ponomarov and Holcomb (2009) were among the first to propose a definition for resilient SCs. In one of the most-cited studies on RSCM, they define resilience in a SC context as "the adaptive capability of the SC to prepare for unexpected events, respond to disruptions, and recover from them by maintaining continuity of operations at the desired level of connectedness and control over structure and function." [Ponomarov and Holcomb, (2009), p.131]. A central aspect of RSCM is its connection to supply chain risk management (SCRM) (Qazi and Gaudenzi, 2016). Some authors regard SC resilience as a core element of SCRM (Ponomarov and Holcomb, 2009; Dinh et al., 2012; Barroso et al., 2015). Other authors point out that RSCM features more proactive elements, meaning that companies should try to avoid risks and to mitigate possible damages in advance (Beermann, 2011; Kamalahmadi and Parast, 2016; Pettit et al., 2010). Although proactive SC reengineering also plays a role in SCRM (Ponomarov and Holcomb, 2009), it can be said, that in RSCM proactive elements generally are of greater importance in comparison to SCRM (Ehrenhuber et al., 2015; Ouabouch, 2015). Moreover, the literature on RSCM emphasises the importance of innovation (Beermann, 2011) and the difference between dealing with statistical uncertainties (as in traditional SCRM) and unpredictable risks and 
the unknown (as in RSCM) (Pettit et al., 2010; Kamalahmadi and Parast, 2016). These aspects expand the resilience concept and broaden the traditional SCRM view (Fiksel et al., 2015). Consequently, RSCM contains many features of SCRM while adding new ones, thereby creating a more holistic view on SCM (Christopher and Peck, 2004; Pettit et al., 2013).

Parallel to the variety of definitions and concepts, several formative elements of RSCM have been discussed in the literature. We have identified five SC characteristics that have been frequently mentioned as being important for achieving SC resilience: redundancy, efficiency, agility, collaboration and flexibility. Redundancy helps to maintain the response capacity of a SC after being disrupted through investments in capital and capacity, e.g., by maintaining multiple suppliers and running operations at low capacity utilisation (Rice and Caniato, 2003; Sheffi and Rice, 2005; Azevedo et al., 2013; Sawik, 2013). In contrast to SSCM, efficiency in a resilience context refers to the efficiency of a SC's response to disruptive events (Scholten and Schilder, 2015; Kamalahmadi and Parast, 2016). Agility relates to the capability of responding rapidly to changed conditions (Ponomarov and Holcomb, 2009). Enablers are dynamic structures, relationship configuration, and end-to-end visibility of information (Baramichai et al., 2007; Christopher and Peck, 2004). Velocity (e.g., achieved by reducing in-bound lead times of information) is also considered within this element (Christopher and Peck, 2004). Collaboration encompasses synergies among partners, joint planning and information exchange (Scholten and Schilder, 2015). Examples are information and resources sharing, goal congruence, decision synchronisation, incentive alignment, collaborative communication and joint knowledge creation (Cao et al., 2010). Flexibility sets focus on taking different positions according to various situations, including flexible transportation systems, flexible supply bases and flexible labour arrangements (Kamalahmadi and Parast, 2016).

\subsection{Conceptual relationships between SSCM and RSCM}

Some formative elements of SSCM and RSCM are highly dependent, overlapping and do not come without contradictions. With respect to SSCM, we argue that value creation can be subsumed under TBL focus, as the objectives of profit and market share maximisation are inherent to achieving economic sustainability. We also think that flow management and performance are general and implicit objectives of any SC. Therefore, we do not consider these elements explicitly in our analysis of the sustainability-resilience nexus. We furthermore regard the formative element of SSCM coordination as closely related to the RSCM element collaboration. Although having different objectives (sustainability and resilience, respectively) both elements refer to the coordination of joint efforts within and between organisations. Thus, we summarise these elements under coordination and collaboration.

Furthermore, efficiency is not undisputed within the literature. As outlined above, efficiency is seen as part of both SSCM and RSCM. Yet, the respective focus and scope is different. While in SSCM efficiency refers to the efficient use of resources, in RSCM it describes the efficiency of responding to disruptions in the SC. We therefore suggest distinguishing between resource efficiency and response efficiency. Moreover, some authors argue that increasing resource efficiency has made SCs vulnerable to external disruptions (Levalle and Nof, 2015; Scholten and Schilder, 2015; Pettit et al., 2010; 
Fahimnia and Jabbarzadeh, 2016). In turn, improving a SC's resilience can make it more inefficient with regard to the use of resources (e.g., because of increased supplier redundancy) which exercises a negative influence on economic sustainability because of increased costs (Barroso et al., 2015). Consequently, in terms of RSCM, redundancy is generally not considered to be efficient (Christopher and Peck, 2004; Carvalho and Cruz-Machado, 2011; Christopher and Holweg, 2011; Pettit et al., 2010; Ivanov et al., 2013; Barroso et al., 2015).

Companies that aim for a resilient SC need to be able to quickly adapt to disruptions through sourcing their inputs from a flexible or redundant supplier base, which enables a company to switch suppliers when production is in danger. This can be facilitated by holding close ties to suppliers to create visibility and trust, which in turn improves information flows and helps to identify disruptions faster (Carvalho et al., 2014). Here, an interesting link to SSCM is created, where long-term relationships are also considered to be crucial. Sawik (2013), however, mentions that supplier protection, the creation of redundancies and long-term-relationships are important parts of RSCM and can conflict with flexibility. To our knowledge, this contradiction has not been addressed properly in the SCM literature so far.

Figure 1 Conceptual framework for sustainable and RSCM

SCM objective

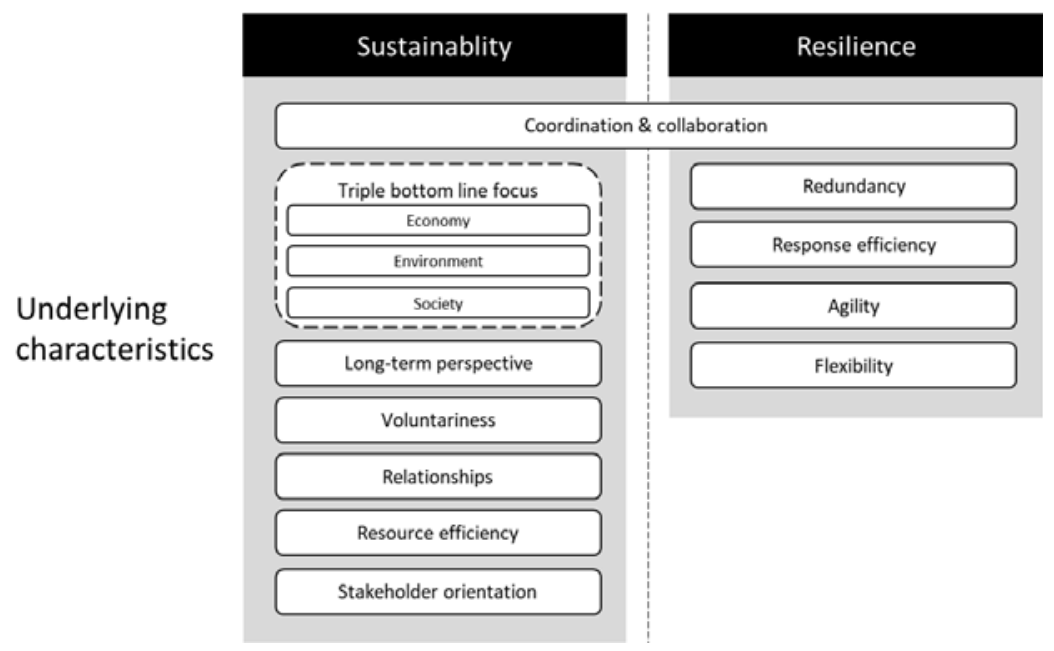

Lastly, flexibility is sometimes seen as part of SC agility (Prater et al., 2001; Cabral et al., 2012) with a controversial relationship towards redundancy, considered in some cases to increase flexibility, and in others it is said to juxtapose with it (Zsidisin and Wagner, 2010; Jüttner and Maklan, 2011). Based on these considerations we propose a novel conceptual SCM framework that incorporates notions from both sustainability and resilience research (Figure 1). In the following sections, we will confront this theoretical framework with practical insights to derive propositions that can be of guidance for future research. 


\section{Methods}

\subsection{Sample and data collection}

Due to the explorative nature of our research we opted for a case study, having the advantage of providing a profound (rather than broad) picture of the topic of interest and allowing to derive theory from empirical observations (Eisenhardt, 1989; Golicic et al., 2005). We chose the automotive industry as object of investigation due to its highly complex, dynamic and global SC and its exposure to both climate change mitigation and adaptation issues, requiring innovations in manufacturing and SCM practices (IEA, 2015; PwC, 2007).

Table 1 Companies participating in the case study

\begin{tabular}{|c|c|c|c|c|}
\hline Company* & No. of employees & Business area & Position in SC & $\begin{array}{c}\text { Interviewee's } \\
\text { position }\end{array}$ \\
\hline Company A & 9,100 & $\begin{array}{l}\text { Parts supplier and } \\
\text { full car assembly }\end{array}$ & Tier $1+2$ & $\begin{array}{c}\text { Global director } \\
\text { SCM }\end{array}$ \\
\hline Company B & $\begin{array}{c}130,000(60,000 \\
\text { in automotive) }\end{array}$ & Parts supplier & Tier 1 & $\begin{array}{c}\text { Manager } \\
\text { environmental } \\
\text { compliance } \\
\text { engineering }\end{array}$ \\
\hline Company $\mathrm{C}$ & 8,050 & $\begin{array}{c}\text { Development and } \\
\text { testing of } \\
\text { automotive } \\
\text { products }\end{array}$ & Tier 1 & $\begin{array}{c}\text { Director global } \\
\text { SCM }\end{array}$ \\
\hline Company D & 12 & $\begin{array}{l}\text { Knowledge } \\
\text { transfer and } \\
\text { networking }\end{array}$ & - & $\begin{array}{l}\text { Project manager } \\
\text { automotive }\end{array}$ \\
\hline
\end{tabular}

Note: *For reasons of confidentiality the real names of the companies are not stated here.

We applied a purposive sampling strategy due to its advantage of enabling the researcher to select appropriate cases for answering the research questions (Neuman, 2011). We only considered companies that conduct major parts of their business in the automotive industry. Because of practical restrictions, we limited our sample to automotive suppliers with headquarters or subsidiaries in Austria. We did not select companies based on firm size, given that using size as an indicator would limit the range of information and could bias the results. After contacting several potential automotive companies, three agreed to share relevant information. All three are key players in the global automotive industry, they are part of extensive international SC networks and can hence be considered as representative cases of a typical automotive supplier. Moreover, we included an industry association to broaden the perspective and for triangulation purposes (see Table 1).

Two ways of information gathering were chosen. First, we conducted a desk research, collecting data from CDP (formerly Carbon Disclosure Project), corporate websites, and annual and sustainability reports to get an overview of companies' climate change related activities. Second, we conducted semi-structured interviews with senior managers responsible for SCM (see Table 1). Before conducting the interviews, we constructed a guide, which allowed for directing the interview within the preferred content focus while ensuring comparability between the interviews (King, 2004). 
The basic structure of the guide was derived from the literature review. Information obtained from the desk research helped to adapt the questions to each company and was used for triangulation later in the data analysis. The interview guide consisted of four sections:

1 general information on the company, its SC and perception of climate change

2 the company's approach to sustainability (climate change mitigation) and related activities

3 the company's approach to resilience (climate change adaptation) and related activities

4 overlaps and trade-offs between sustainability (mitigation) and resilience (adaptation) (see Appendix).

Interviewees were given freedom to bring up new topics to ensure that additional information could be provided that was relevant for the research but not covered by the interview guide (King, 2004).

Four interviews were conducted in total, two face-to-face and two via telephone and each lasted up to one and a half hours. The interviews were conducted in German to avoid communication barriers and were carried out by the same two researchers to ensure comparability. The interviews were recorded with permission of the interviewees and transcribed for further analysis.

\subsection{Data analysis}

We analysed the gathered data based on a qualitative content analysis comprising an inductive and a deductive part (Krippendorff, 2003). Deduction was used to systematically analyse the interviews regarding the concepts of SSCM and RSCM (Mayring, 2010). We independently coded the interview transcripts by using the characteristics of SSCM and RSCM (Figure 1) as categories. An inductive approach complemented the data analysis to avoid omitting important information not covered by the theoretical framework (Eisenhardt, 1989; Mayring, 2010). During the inductive analysis, the interview transcripts were screened and clustered according to emerging topics that could not be assigned to the formative elements established before. Afterwards, we extracted relevant information and compared the findings amongst the companies to detect company-specific and generalisable patterns. Lastly, we confronted our key findings with the theoretical background established in the literature review.

\section{The practical perspective: managing climate change issues in the automotive SC}

\subsection{SC characteristics}

When asked about the key characteristics of their SCs, the interviewed managers named many common keywords: agile, innovative, global, highly dynamic, and highly complex (in the case of company A and B comprising over 10,000 suppliers). We detected two 
major trends with high relevance for the focus area of this paper - climate change. First, all companies pointed out that the development of the automotive industry's SC requires global (long-distance) sourcing. Especially the two series-producers (A and B) stressed the tendency towards long-distance sourcing as a reaction to the extreme pressure for low prices. The second trend in automotive manufacturing is a reduction of suppliers' independence. OEMs increasingly opt for contract manufacturing with customer-directed suppliers, meaning that first tier suppliers merely assemble parts from other suppliers further upstream that are chosen by the OEM. While the OEM thereby seizes control over almost the whole SC, the contract manufacturer's influence is vastly reduced. According to company A, this minimised leeway in sourcing leads to reduced information about their suppliers, also in the field of sustainability and resilience. The company's sustainability standards for sourcing are overruled when OEMs issue directives for their suppliers. According to company B, this trend comes along with the OEM's attempts to increasingly in-source their production.

\subsection{Perception of climate change}

The two sides of climate change - the companies' needs and means of mitigation and the impacts they are exposed to - were regarded differently throughout the interviews. While for company A climate change was "not a topic to focus on", company B expressed the need for climate action to retain competitiveness, and company $\mathrm{C}$ explained its significant efforts for climate-related action with the long-term focus inherent to its family-owned business: "...capital companies think in quarters, family businesses in generations." According to the company representative, these efforts are mainly due to the indirect effects of climate change, in particular stakeholder and customer pressures but also due to reputational risks. However, legislation was also seen as being conducive. Company $\mathrm{C}$ and company $\mathrm{D}$ even demanded higher regulatory pressure, assuming that otherwise, changes would not occur because of policy uncertainty. Moreover, company A expressed that appropriate corporate communication is critical for preventing new restrictive environmental laws from becoming a risk. Apart from that, the interviewed companies were largely indifferent regarding direct climate change impacts (e.g., extreme weather events) and if not, translated those impacts into potential negative economic consequences for the company, as this quote from company B shows: "We are confronted with rising product prices due to climate change effects frequently". The interviews also showed that suppliers are mostly worried about legislation and OEM demands related to climate change adaptation and related effects for their business, exemplified by company B's statement that "the largest risk is always the OEM."

Only company $\mathrm{C}$ reported opportunities related to climate change. Due to its pioneering role in 'green' power-train technology, stricter regulations on emissions are considered a positive factor. Furthermore, during a recent flooding, its agile and highly globalised structure of branches allowed the company to offer services and equipment to other SC companies affected by the event. Hence, company $\mathrm{C}$ not only helped to minimise negative effects but also took on the opportunity to generate profitable business. 


\subsection{Views on SSCM}

\subsubsection{Triple bottom line}

Concerning the TBL approach of sustainability, company A declared that environmental efforts, such as emission reduction activities, without monetary gains are 'hardly realisable'. Such activities are implemented, however, when demanded by the OEM, as the company expects that in this case investments in sustainability activities pay off in the long run. Company B was familiar with the TBL approach and explained accordingly that they choose their own suppliers based on social and environmental criteria. Yet, they also stated that there is no reason for them to engage in sustainability in their SC without potential economic benefits by expressing that "additional costs are always difficult." The company rather considers sustainability as beneficial when it is about catching up with competitors (by increasing competitiveness) or when it enables the company to comply with legislation. Company $\mathrm{C}$ stated that the TBL approach is integrated into their supplier selection processes through environmental variables such as emissions and waste water treatment, but also social indicators.

\subsubsection{Long-term perspective}

When it comes to the long-term perspective of SSCM, we mainly focused on product lifecycle (e.g., LCA) and EoL issues. Although company $\mathrm{C}$ did not specifically refer to the use of these instruments, it emphasised to have an overall long-term interest in sustainability issues. Company B explicitly mentioned how their business is aiming at designing low-carbon strategies by carrying out LCAs for their products and ensuring that newly developed products have lower overall carbon footprints than previous versions. Conversely, company A declared that long-term product maintenance and the EoL dimension are not highly prioritised.

\subsubsection{Voluntariness}

When asked about the relevance of climate change mitigation for their business, companies predominantly answered that they rather have an instrumental than a proactive approach to it, which is related to the (in)voluntary nature of sustainability-related SC activities. In some cases, a sustainable outcome was simply achieved as a collateral effect of responding to climate change impacts because of perceived business opportunities rather than taking proactive action (e.g., when a company decides to produce power trains for electric cars due to market pressures, which is associated with environmental benefits. Clear examples are companies A and B, which regard sustainability as a side effect of their optimisation processes (i.e., eco-design efforts and cleaner production, transportation and mobility projects) but not as their main goal. Particularly in the absence of OEM demands, the interviewed companies did not see the importance of sustainability projects from an economic perspective, given their limited resources and that other industry and competition-related topics are perceived as more important. On a smaller scale however, voluntary sustainability efforts play a role: company B for instance implemented a support scheme for voluntary engagement of their employees in sustainability projects, also outside the company. 


\subsubsection{Coordination and collaboration}

As for coordination activities related to SSCM and climate change mitigation in particular, company B, for example, has established global councils in different areas that oversee the development of sustainability strategies and related decision-making processes for the firm. They also cooperate with other companies, e.g., for the developments of their LCAs stating that "without (cooperation), it would not work at all." In company $\mathrm{C}$, all the departments of the firm are assigned with specific responsibilities regarding sustainability and managed through their quality control department at a 'top-management level', where yearly audits are conducted and tailored sustainability measures developed.

\subsubsection{Relationships}

The most important relationship of the interviewed suppliers is the one with their customers. These relationships are mainly determined by the power of OEMs over their suppliers, rather than being a relationship where suppliers are perceived as equal partners. OEMs are perceived as key influencers and pressure from automotive OEMs on their suppliers is relatively high, particularly concerning prices and sustainability-related issues, such as data on GHG emissions and legal compliance.

Concerning upstream SC relationships, the interviewed companies expressed that, under the above-mentioned pressures from OEMs, they have implemented scouting and evaluation processes to select their suppliers. Company B, for example, has developed a system to carry out an overall assessment of their suppliers and an 'approved supplier list', applicable to all national and international subsidiaries and based on the same indicators demanded by OEMs (mainly economic and environmental criteria). Company $\mathrm{C}$ explained that they carry out audits with their suppliers, especially on sustainabilityrelated matters. Nonetheless, for them, supplier choice cannot be customer-driven only, since they consider their production to be high-end (reflected by low quantities and highly customised products), which is why their suppliers are not easily replaceable and have a very strong position within their SC. Hence, maintaining a long-term relationship with their suppliers is a factor of high importance.

\subsubsection{Resource efficiency}

Efficiency was perceived as the most important formative element of sustainable SCs. All companies stated that, particularly in the automotive industry, efficiency plays a major role in SCM strategies, and that constant actions are taken to improve efficiency wherever possible. Company $\mathrm{C}$ explained: "Efficiency ranks very high. We are chased by the OEMs that probably have the most aggressive purchasing policy there is." This is in line with other studies, highlighting that efficiency is perceived as a main driver for change in SC structures (Mari et al., 2014). Resource efficiency was mostly approached by the interviewees from a point of view which connects efficiency with cost savings, e.g., in the case of energy efficiency. Other meanings of efficiency, e.g., efficient communications or process efficiency, were mentioned only partially and considered less important in the context of climate change mitigation. 


\subsubsection{Stakeholder orientation}

In contrast to company $\mathrm{A}$, companies $\mathrm{B}, \mathrm{C}$ and $\mathrm{D}$ consider stakeholder engagement to be a relevant topic. Company B stated that their most important stakeholders are their customers, who exercise high pressure given that they often request corporate and SCrelated information. Company $\mathrm{C}$ referred to the claims of local communities, in which their operations are based and by which the company is affected. Company D, on the other hand, stated that there are many conflicts of interest between their stakeholders, ranging from change-oriented environmentalists to more conservative OEMs and oil companies pushing for continued sales of combustion engines for as long as possible. The different interest groups are found to "always stick to their perspective, not seeing the bigger picture", even though a "balance of all interests would be required."

\subsection{Views on RSCM}

\subsubsection{Redundancy}

Redundancies were in general regarded as a negative element by the interviewed companies. Company $\mathrm{C}$ mentioned that redundancies were avoided wherever possible. Company A argued that redundancies were too costly to be implemented and therefore undesirable. In line with the findings indicating the importance of resource efficiency as outlined earlier, the companies try to hold their SC as lean as possible. The interviewed suppliers thus rather aim for resource-efficient instead of redundant SC structures. Company $\mathrm{C}$ also claimed to reduce redundancies concerning inventories. Nevertheless, optional redundancy played a major role because the company established a supplier portfolio with information about potential alternative suppliers and their financial situation. In this case, redundancies in supplier management helped the company to increase SC flexibility in case of disruptions.

\subsubsection{Response efficiency}

Especially companies A and B largely rely on a global supplier base and long-distance sourcing driven by OEMs' demands for cost reductions. For company B, however, there can be cases where products 'need to be sourced locally for risk reasons'. Being less affected by this pressure, company $\mathrm{C}$ also built up a global sourcing basis, but for different reasons. Though partly associated with quality losses, long-distance sourcing enabled the company to build up a geographically diverse supply base, thus offering fast responses (e.g., to customer demands) in almost all parts of the world, even if one region was affected by extreme weather events or other disturbances. Yet, this global SC setup entails environmental drawbacks. Not only are long transportation ways more carbon intensive than locally sourced materials, but it was also pointed out that a SC with bases in various regions of the world is more prone to be affected by major climatic events, such as extreme weather, potentially leading to supply interruptions.

\subsubsection{Agility}

Agility was a frequently mentioned and highly important aspect during the interviews. For example, company A claimed to have "high ambitions within the company" towards more agility. Company B viewed the whole automotive SC to be one of the most agile 
ones, which is in line with findings of Cabral et al. (2012), who found out, that, e.g., for Volkswagen, agility was the most relevant element in SCM. Company D stated that "whereas smaller companies can work in a more agile way, the process has to go through more steps in bigger companies", which emphasises the importance of, e.g., decreasing in-bound lead-times for bigger companies with more complex information flows (Christopher and Peck, 2004).

Furthermore, visibility was perceived as a driver for SC agility. During the interviews, it became evident, that visibility - or in other words - transparency, within the $\mathrm{SC}$ is of great importance for companies. For example, company B's internal aim is to achieve complete visibility within its SC. Company A referred to increasing legal and stakeholder requirements in this context. Visibility helped the interviewed companies not only to increase the agility of their SCs due to a higher quality and quantity of information, but also helped them to be able to make informed choices when selecting suppliers.

\subsubsection{Coordination and collaboration}

Deviating from the SSCM perspective, the interviews did not indicate that SC collaboration constitutes a major factor in RSCM. Company A stated that collaboration and partnerships, especially with suppliers with a similar product portfolio, "are always a difficult topic [...] because in other fields they can be our competitors." Company B regarded collaboration as a tool for innovation and the integration of new ideas rather than as part of RSCM and collaborates regularly with suppliers during innovation processes, fostering joint knowledge creation. This focus on mutual benefits is in line with findings from Scholten and Schilder (2015).

Another important aspect of SC collaboration is information sharing. Higher transparency, which was named as key driver for collaboration by company $\mathrm{C}$, was positively related to trust and therefore seen as enabler for SC collaboration. Nevertheless, company B stated that self-reporting of suppliers sometimes is not sufficient to create a trustworthy profile of the respective supplier, which is why further information is acquired through internal research. The companies' supplier evaluations are mainly based on financial stability indicators, but also on the implementation of sustainability aspects within the companies, social commitment and innovation power.

\subsubsection{Flexibility}

A flexible supply base was rated as important for resilience by the companies, but also as very difficult to achieve due to the importance of and dependence on key suppliers and suppliers with high levels of specialised know-how. Flexibility was also regarded by company A as allowing "the saving of resources through flexible assembly lines and through more flexible reaction to customer wishes," which in turn was seen as an enabler of (economic) sustainability in SCs. However, company D emphasised on trade-offs between flexibility and long-term relationships between suppliers and customers and called for a 'middle way' to achieve both. This is because long-term contracts can reduce the buyer's flexibility of switching to other suppliers in cases of SC disruptions. Low flexibility might also hamper economic sustainability, e.g., if a supplier's business heavily depends on orders from a single customer and if this customer experiences financial problems. 


\subsection{Findings complementing the literature-based framework}

The information obtained from the case study shows that the formative elements derived from the literature cover most but not all critical premises of sustainable and resilient SCs. Apart from a number of aspects found in the literature that were confirmed to be relevant for SSCM and RSCM in the case study, we identified two additional elements that can be considered as crucial for the success of both sustainability and resilience strategies in SCs: transparency and diversity. We consider both to be enabling factors, since it can be derived from the interviews that they have a facilitating relationship with various characteristics of both SSCM and RSCM, rather than directly affecting the outcomes of SCM practices.

\subsubsection{Transparency}

During our analysis, it became clear that the SCM elements coordination, collaboration, stakeholder orientation and agility benefit from transparency as underlying prerequisite, which is in line with research on RSCM (Carvalho et al., 2014; Ehrenhuber et al., 2015) and the importance of the visibility of changes in the SC (Christopher and Peck, 2004). According to our interviews, companies have recognised the significance of transparency. All companies interviewed make use of SC mapping tools (software that allows for better transparency along their SCs) and/or the international IMDS database, which provides information on all materials used in the automotive industry. Notably, higher transparency is sought by the companies, but these efforts also entail additional costs. Company A achieves almost full monitoring of their first-tier suppliers but does not go further upstream for cost reasons. Company B implemented what they call a "sourcing table" with the objective of having an internal body that approves all sourcing decisions, and major suppliers must fulfil the criteria of an 'approved suppliers list', also comprising sustainability requirements.

The conditional nature of transparency becomes clear when understanding that it usually is not an objective itself but rather serves as a necessary condition for other formative elements such as coordination and collaboration, but also stakeholder orientation (the non-profit organisation CDP, for example, entirely rests on transparency efforts) and sometimes flexibility or agility, as they require readily available and detailed knowledge about other SC members. Transparency is furthermore a critical premise for ambitious climate protection efforts. Only when knowing where and how emissions occur in the SC can effective measures be taken. The example of company A shows that a lack of stakeholder pressure made transparency efforts beyond the legal requirement to be perceived as entailing unnecessary costs, which also hampered the implementation of ambitious mitigation strategies within the company and its SC.

\subsubsection{Diversity}

When looking at SC strategies of the companies interviewed, diversity evolved as one of the essential underlying factors, especially regarding resilience. Diversity in SCM has many dimensions, the most important ones according to our results are regional, supplier, customer and product diversity, each of which leading to higher levels of sustainability or resilience as the following examples show. 
Company $\mathrm{C}$ explained how their global presence (regional diversity) enables them to bridge sudden interruptions in their SC, guaranteeing reliability without redundancies. Company B presented an example of a high single source dependency which could be overcome by a greater supplier diversity: "We had a big problem with the natural latex we used for our green seat. Due to civil war in the sourcing country, it became more and more expensive and was at some point not available." Company D explained how the long-term focus on one customer can lead to dependencies, threatening a company's existence and showing the importance of customer diversity: "The sudden cancellation of an order can pose risks as seen recently in the VW scandal: a small-scale enterprise had built facilities for an Audi order, which was suddenly held back due to the crisis. The small companies are not insured like larger ones, therefore, they face enormous risks." Company D also provided examples of SMEs that entered new markets outside of the automotive industry to extend their product portfolio and minimise potential risks caused by changes in consumer attitudes or climate policies.

As is the case with transparency, also diversity can be an enabler for at least three other elements, namely response efficiency, flexibility and agility (above examples of companies B and C) and economic sustainability (example of company D). Diversity especially improves flexibility as it allows companies to reposition themselves according to requirements (examples from company D), but without a conflicting relationship to redundancy. As the above examples show, diversity is crucial for climate change resilience especially, knowing that in the future reasons for SC perturbations might increasingly be climate-related.

\subsection{Overlaps and trade-offs between SSCM and RSCM}

Overall, we observed that resilience in the context of climate change and SCM played a minor role when compared to sustainability and that it was often more related to the management of general supply-related disruption risks. This is an interesting finding in the sense that other research suggests differently and ascribes more (practical) importance to RSCM (Kamalahmadi and Parast, 2016). Based on the literature review and the empirical findings outlined in the last two sections, we make the following research propositions that should be addressed in more detail in future studies on the sustainability-resilience nexus:

P1 The integration of environmental and social criteria in supplier selection processes limits the flexibility in supplier selection and thus the potential supply base, which decreases SC resilience.

P2a A flexible and agile supplier/customer base (enabled by supplier/customer diversity) helps to increase both SC resilience and sustainability (e.g., when alternative suppliers are needed in case of disruptions caused by supply shortages, or when there are financial problems on the customer side, on which the supplier's business is highly dependent).

P2b A flexible supplier base compromises the ability of maintaining long-term relationships with key suppliers (e.g., due to the necessity of flexible contracts) and thus impairs sustainability efforts. 
P3 A focus on long-term relationships decreases flexibility (e.g., due to fixed long-term contracts), which is detrimental to SC resilience.

P4 Improvements in resource efficiency lead to the minimisation of redundancies and thus impair SC resilience.

P5 Transparency facilitates collaboration and coordination efforts, stakeholder engagement and flexibility/agility and can therefore be a driver for both SC sustainability and resilience.

P6 A regionally diverse supply base is detrimental to SC sustainability due to longer transport distances and associated environmental impacts.

P7 A diverse (global) supply base improves response efficiency in case of (regional) disruptions and thus increases SC resilience.

We furthermore propose the following conceptual model for an integrated perspective on resilience and sustainability in the context of SCM (Figure 2). It also shows the proposed interactions between the elements of SSCM and RSCM.

Figure 2 Relationships between SSCM and RSCM

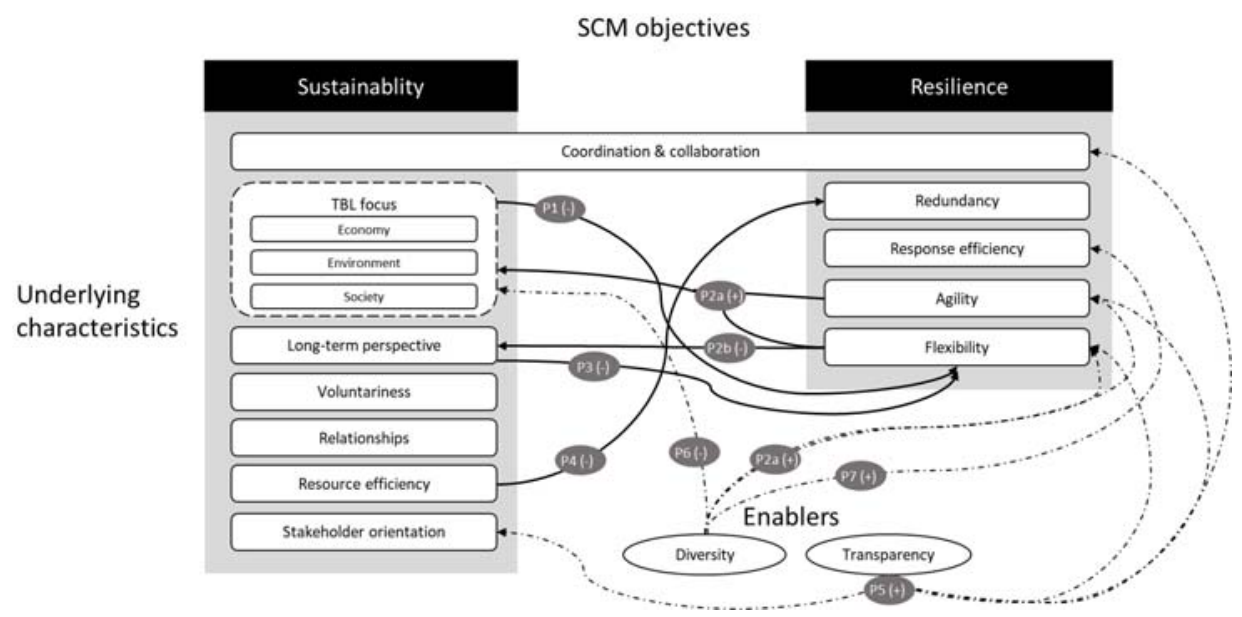

\section{Conclusions}

Coping with climate change issues includes practices oriented towards sustainability and resilience, especially in diverse and globalised SCs. To date, there is little research addressing the integration of elements that enable both resilient and SSCM. In this article, we explored the relationships between these concepts theoretically as well as empirically based on a case study of suppliers in the automotive industry. From the key findings several important implications for future research and practitioners can be derived.

Although sustainability and climate change mitigation are not a novelty for automotive suppliers, resilience and climate change adaptation remain emerging and fast changing topics, and as such, they have not been addressed comprehensively yet. We 
found that the way climate change is perceived by suppliers in the automotive industry can vary greatly. The motivations for both, sustainability and resilience efforts in SCM are diverse and not primarily related to immediate concerns about climate change mitigation or adaptation, but rather to external pressure exerted by stakeholders and legislation or to the long-term positioning of suppliers for achieving competitive advantages. According to the interviews, however, the biggest concern related to climate change are pressures from customers and especially OEMs.

In our study, we have deduced formative elements of both SSCM and RSCM from existing literature and confronted them with practical insights from SC managers. Regarding the formative elements reviewed, the key takeaways for both SSCM and RSCM are the following. Coordination and collaborations within and between organisations are valuable and relevant aspects for both SSCM and RSCM. For SSCM specifically, resource efficiency was perceived as a crucial SC characteristic and as the main driver for change when associated with cost reductions. We also discovered that the perception of sustainability as a long-term issue is highly variable from company to company and pursuing a TBL approach is mostly not prioritised unless explicitly requested by OEMs (e.g., due to legislations or increased competition). This finding also indicates that sustainability efforts are often not implemented on a voluntary basis. When it comes to stakeholder engagement, the analysed companies recognise its relevance, yet they also acknowledge it as a highly complex process. In terms of relationships with other companies, the interviewed automotive suppliers clearly prioritise their customers, although the perception is that the relationship is one of power, dominated by the OEM, rather than a partnership. On the RSCM side, we found that response efficiency with regard to disruptions is sought by global and diverse SCs, with agility playing a central role, and flexibility being highly valued. Redundancies, in contrast, are considered to be costly and thus, undesirable.

Our findings also indicate several conflicting and supporting relationships between the formative elements of sustainable and RSCM. For example, flexibility was recognised as an element of resilience in the SC while - at least partially - standing in contrast to long-term relationships with suppliers as would be, according to the literature, required for SSCM. Similarly, redundancies, even though potentially beneficial for the resilience of SCs, were typically overruled when efficiency concerns arose. Additionally, based on information from the case study, two supporting SC characteristics have been found that can act as enablers of other formative elements of SSCM and RSCM, respectively. These were

1 transparency, as an important premise for coordination and collaboration, stakeholder orientation and to a certain degree agility and flexibility (regional, supplier, customer and product)

2 diversity as an enabler of response efficiency, agility, flexibility and economic sustainability.

Our empirical findings help managers to identify interfaces between the concepts of SSCM and RSCM. By showing these connections and by revealing trade-offs and overlaps, we support managers in making informed choices based on both resilience and sustainability-oriented views. The identification of the two enabling elements transparency and diversity sheds light on important underlying factors that need to be addressed for successful SCM practices that aim at sustainability and resilience. Our 
study furthermore suggests that there are reasons to assume that transparency, the integration of the TBL approach into SCM and stakeholder engagement can increase corporate competitiveness. Achieving competitive advantages could therefore be a desirable side effect of pursuing a sustainable or RSCM strategy.

Based on our findings, we suggest the following three avenues for further research. First, our findings indicate several conflicting and supporting relationships between the formative elements of sustainable and RSCM. For example, flexibility was recognised as an enabler of sustainability in the SC while - at least partially - standing in contrast to long-term relationships with suppliers. However, the precise relationships between the different formative elements and their impacts on each other in both positive and negative ways, is still weakly founded and should be investigated in further empirical research. Hereby especially the holistic assessment of trade-offs between the formative elements remains insufficiently addressed (Christopher and Peck, 2004; Ivanov et al., 2013; Kamalahmadi and Parast, 2016). Understanding potential trade-offs is particularly important for the detection of possible path dependencies concerning a company's SCM. Second, our research propositions should be empirically tested based on larger sample sizes. We deem it especially important to generate more profound empirical information on how exactly the characteristics of SSCM and RSCM relate to the two enabling elements transparency and diversity. Finally, our case study was conducted amongst four companies that partially overlap in SCs and region. This leads to a higher consistency and better comparability of findings, but a generalisation or transfer of results to other industries or regions is hardly possible, since both external conditions and managerial practices may vary. Consequently, we suggest further cross-industrial and cross-regional studies with a greater number of companies.

\section{Acknowledgements}

This work was funded by the Austrian Science Fund under research grant W1256-G15 (Doctoral Programme Climate Change - Uncertainties, Thresholds and Coping Strategies) and received support from CONACYT and the Mexican Ministry of Energy (SENER) under grant no. 412561. The research was equally undertaken by the first four authors, while the last author served as supervisor and was involved in the writing process.

\section{References}

Ahi, P. and Searcy, C. (2013) 'A comparative literature analysis of definitions for green and sustainable supply chain management', Journal of Cleaner Production, Vol. 52, pp.329-341 [online] http://www.sciencedirect.com/science/article/pii/S095965261300067X.

Azevedo, S.G., Govindan, K., Carvalho, H. and Cruz-Machado, V. (2013) 'Ecosilient Index to assess the greenness and resilience of the upstream automotive supply chain', Journal of Cleaner Production, Vol. 56, pp.131-146 [online] http://www.sciencedirect.com/science/ article/pii/S0959652612001989.

Baramichai, M., Zimmers, E.W. and Marangos, C.A. (2007) 'Agile supply chain transformation matrix: an integrated tool for creating an agile enterprise', Supply Chain Management: An International Journal, Vol. 12, No. 5, pp.334-348. 
Barroso, A.P., Machado, V.H., Carvalho, H. and Cruz Machado, V. (2015) 'Quantifying the supply chain resilience', in Tozan, H. (Ed.): Application of Contemporary Management Approaches in Supply Chains, InTech, Rijeka, pp.13-38.

Beermann, M. (2011) 'Linking corporate climate adaptation strategies with resilience thinking', Journal of Cleaner Production, Vol. 19, No. 8, pp.783-904.

Burgess, K., Singh, P.J. and Koroglu, R. (2006) 'Supply chain management: a structured literature review and implications for future research', International Journal of Operations \& Production Management, Vol. 26, No. 7, pp.703-729.

Cabral, I., Grilo, A. and Cruz-Machado, V. (2012) 'A decision-making model for lean, agile, resilient and green supply chain management', International Journal of Production Research, Vol. 50, No. 17, pp.4830-4845.

Cao, M., Vonderembse, M.A., Zhang, Q. and Ragu-Nathan, T.S. (2010) 'Supply chain collaboration: conceptualisation and instrument development', International Journal of Production Research, Vol. 48, No. 22, pp.6613-6635.

Carter, C.R. and Rogers, D.S. (2008) 'A framework of sustainable supply chain management: moving toward new theory', International Journal of Physical Distribution \& Logistics Management, Vol. 38, No. 5, pp.360-387.

Carvalho, H. and Cruz-Machado, V. (2011) 'Integrating lean, agile, resilience and green paradigms in supply chain management (LARG_SCM)', in Li, P. (Ed.): Supply Chain Management, InTech, Rijeka, pp.27-48.

Carvalho, H., Azevedo, S.G. and Machado, V.C. (2014) 'Supply chain management resilience: a theory building approach', International Journal of Supply Chain and Operations Resilience, Vol. 1, No. 1, pp.3-27.

Christopher, M. and Holweg, M. (2011) ' Supply chain 2.0': managing supply chains in the era of turbulence', International Journal of Physical Distribution \& Logistics Management, Vol. 41, No. 1, pp.63-82.

Christopher, M. and Peck, H. (2004) 'Building the resilient supply chain', International Journal of Logistics Management, Vol. 15, No. 2, pp.1-13.

Closs, D.J., Speier, C. and Meacham, N. (2011) 'Sustainability to support end-to-end value chains: the role of supply chain management', Journal of the Academy of Marketing Science, Vol. 39, No. 1, pp.101-116.

Colicchia, C. and Strozzi, F. (2012) 'Supply chain risk management: a new methodology for a systematic literature review', Supply Chain Management: An International Journal, Vol. 17, No. 4, pp.403-418.

Dahlsrud, A. (2008) 'How corporate social responsibility is defined: an analysis of 37 definitions', Corporate Social Responsibility and Environmental Management, Vol. 15, No. 1, pp.1-13.

Derissen, S., Quaas, M.F. and Baumgärtner, S. (2011) 'The relationship between resilience and sustainability of ecological-economic systems', Ecol. Econ., Vol. 70, No. 6, pp.1121-1128.

Di Botonto, S. (2014) Industry Overview - The Automotive Industry in Germany [online] https://www.gtai.de/GTAI/Content/EN/Invest/_SharedDocs/Downloads/GTAI/Industryoverviews/industry-overview-automotive-industry-en.pdf (accessed 11 June 2016).

Dinh, L.T., Pasman, H., Gao, X. and Mannan, M.S. (2012) 'Resilience engineering of industrial processes: principles and contributing factors', Journal of Loss Prevention in the Process Industries, Vol. 25, No. 2, pp.233-241.

Ehrenhuber, I., Treiblmaier, H., Nowitzki, C.E. and Gerschberger, M. (2015) 'Toward a framework for supply chain resilience', International Journal of Supply Chain and Operations Resilience, Vol. 1, No. 4, pp.339-350.

Eisenhardt, K.M. (1989) 'Building theories from case study research', Academy of Management Review, Vol. 14, No. 4, pp.532-550. 
Fahimnia, B. and Jabbarzadeh, A. (2016) 'Marrying supply chain sustainability and resilience: a match made in heaven', Transportation Research Part E: Logistics and Transportation Review, Vol. 91, pp.306-324.

Fiksel, J., Polyviou, M., Croxton, K.L. and Pettit, T.J. (2015) 'From risk to resilience: learning to deal with disruption', MIT Sloan Management Review, Vol. 56, No. 2, pp.79-86.

Golicic, S.L., Davis, D.F. and McCarthy, T.M. (2005) 'A balanced approach to research in supply chain management', in Kotzab, H. and Westhaus, M. (Eds.): Research Methodologies in Supply Chain Management, Physica-Verlag, Heidelberg, New York, pp.15-29.

Harrison, J.S., Bosse, D.A. and Phillips, R.A. (2010) 'Managing for stakeholders, stakeholder utility functions, and competitive advantage', Strategic Management Journal, Vol. 31, No. 1, pp.58-74.

Hassini, E., Surti, C. and Searcy, C. (2012) 'A literature review and a case study of sustainable supply chains with a focus on metrics', International Journal of Production Economics, Vol. 140, No. 1, pp.69-82.

Holling, C.S. (1973) 'Resilience and stability of ecological systems', Annual Review of Ecology and Systematics, Vol. 4, No. 1, pp.1-23.

International Energy Agency (IEA) (2015) CO2 Emissions from Fuel Combustion. Highlights, International Energy Agency, Paris, France.

Ivanov, D., Sokolov, B. and Dolgui, A. (2013) 'The ripple effect in supply chains: trade-off 'efficiency-flexibility-resilience' in disruption management', International Journal of Production Research, Vol. 52, No. 7, pp.2154-2172.

Jüttner, U. and Maklan, S. (2011) 'Supply chain resilience in the global financial crisis: an empirical study', Supply Chain Management: An International Journal, Vol. 16, No. 4, pp.246-259.

Kamalahmadi, M. and Parast, M.M. (2016) 'A review of the literature on the principles of enterprise and supply chain resilience: major findings and directions for future research', International Journal of Production Economics, Vol. 171, No. 1, pp.116-133.

Kim, Y., Chen, Y-S. and Linderman, K. (2015) 'Supply network disruption and resilience: a network structural perspective', Journal of Operations Management, Vols. 33-34, No. 1, pp.43-59.

King, N. (2004) 'Using interviews in qualitative research', in Cassell, C. and Symon, G. (Eds.): Essential Guide to Qualitative Methods in Organizational Methods in Organizational Research, Sage, London, pp.11-22.

Krippendorff, K.H. (2013) Content Analysis: An Introduction to Its Methodology, 3rd ed., SAGE Publications, Inc., Thousand Oaks.

Levalle, R.R. and Nof, S.Y. (2015) 'Resilience by teaming in supply network formation and re-configuration', International Journal of Production Economics, Vol. 160, pp.80-93.

Linnenluecke, M.K. and Griffiths, A. (2012) 'Assessing organizational resilience to climate and weather extremes: complexities and methodological pathways', Climatic Change, Vol. 113, pp.3-4.

Mari, S., Lee, Y. and Memon, M. (2014) 'Sustainable and resilient supply chain network design under disruption risks', Sustainability, Vol. 6, No. 10, pp.6666-6686.

Mayring, P. (2010) Qualitative Inhaltsanalyse: Grundlagen und Techniken, 11th ed., Beltz, Weinheim.

Mensah, P. and Merkuryev, Y. (2014) 'Developing a resilient supply chain', Procedia-Social and Behavioral Sciences, Vol. 110, pp.309-319. 
Neuman, W.L. (2011) Social Research Methods: Qualitative and Quantitative Approaches, 7th ed., Allyn \& Bacon, Boston.

Ouabouch, L. (2015) 'Overview on Supply Chain Resilience', Materials Management Review, Vol. 11, No. 9, pp.16-18.

Pettit, T.J., Croxton, K.L. and Fiksel, J. (2013) 'Ensuring Supply Chain Resilience: Development and Implementation of an Assessment Tool', Journal of Business Logistics, Vol. 34, No. 1, pp.46-76.

Pettit, T.J., Fiksel, J. and Croxton, K.L. (2010) 'Ensuring supply chain resilience: development of a conceptual framework', Journal of Business Logistics, Vol. 31, No. 1, pp.1-21.

Ponomarov, S.Y. and Holcomb, M.C. (2009) 'Understanding the concept of supply chain resilience', The International Journal of Logistics Management, Vol. 20, No. 1, pp.124-143.

Prater, E., Biehl, M. and Smith, M.A. (2001) 'International supply chain agility - tradeoffs between flexibility and uncertainty', International Journal of Operations \& Production Management, Vol. 21, Nos. 5/6, pp.823-839.

PricewaterhouseCoopers ( $\mathrm{PwC}$ (2007) The Automotive Industry and Climate Change: Framework and Dynamics of the CO2 (r)evolution, Stuttgart, Germany [online] https://www.pwc.com/th/en/automotive/assets/co2.pdf (accessed 10 June 2017).

Qazi, A. and Gaudenzi, B. (2016) 'Supply chain risk management: creating an agenda for future research', International Journal of Supply Chain and Operations Resilience, Vol. 2, No. 1, pp. $12-50$.

Redman, C.L. (2014) 'Should sustainability and resilience be combined or remain distinct pursuits?', Ecology and Society, Vol. 19, No. 2, pp.37-44.

Rice, J.B., Caniato and F. (2003) 'Building a secure and resilient supply network', Supply Chain Management Review, Vol. 7, No. 5, pp.22-30.

Sáenz, M.J. and Revilla E. (2014) 'Creating more resilient supply chains', MIT Sloan Management Review [online] https://www.researchgate.net/profile/Maria_Saenz4/publication/ 264037785_Creating_More_Resilient_Supply_Chains/links/0a85e53c925ca08eb9000000.pdf (accessed $1 \overline{0}$ June 2017).

Sawik, T. (2013) 'Selection of resilient supply portfolio under disruption risks', Omega, Vol. 41, No. 2, pp.259-269.

Scholten, K. and Schilder, S. (2015) 'The role of collaboration in supply chain resilience', Supply Chain Management: An International Journal, Vol. 20, No. 4, pp.471-484.

Seuring, S. and Müller, M. (2008) 'From a literature review to a conceptual framework for sustainable supply chain management', Journal of Cleaner Production, Vol. 16, No. 15, pp.1699-1710.

Sheffi, Y. and Rice Jr., J.B. (2005) 'A supply chain view of the resilient enterprise', MIT Sloan Management Review, Vol. 47, No. 1, pp.41-48.

Stock, J.R. and Boyer, S.L. (2009) 'Developing a consensus definition of supply chain management: a qualitative study', International Journal of Physical Distribution \& Logistics Management, Vol. 39, No. 8, pp.690-711.

United Nations Framework Convention on Climate Change (UNFCCC) (2015) 'Adoption of the Paris Agreement', 21st Conference of the Parties, United Nations, Paris.

Zsidisin, G.A. and Wagner, S.M. (2010) 'Do perceptions become reality?: The moderating role of supply chain resiliency on disruption occurrence', Journal of Business Logistics, Vol. 31, No. 2, pp.1-20. 


\section{Appendix}

\section{Interview guide}

\section{Part 1: Introduction}

Company and interviewee

1 What is the size of the company?

2 What is the core area of the company's automotive business?

3 Who are the company's customers?

4 What is the function of the interviewee in the company and what is his background?

Supply chain characteristics

5 How would you describe the structure of your supply chain and why?

6 About how many tiers of your supply do you have information?

7 What is the position of the company in the supply chain?

8 How much climate-related information do possess about other companies in the supply chain?

9 In which countries do you have subsidiaries?

10 How important is it for your company to know your supply chain (in detail)? Do you use any special tools (e.g., mapping)?

11 How important are supply chain related information for your customers?

Perception of climate change

12 How do you perceive the importance of climate change mitigation issues?

13 How do you perceive the importance of climate change adaptation issues?

14 Which opportunities and risks do you perceive?

15 Does your company monitor direct/indirect carbon emissions? How do you use this information?

\section{Part 2: Climate change mitigation (sustainable supply chain management)}

Importance of sustainability and climate change mitigation

17 What is your understanding of a sustainable automotive industry?

18 What is your understanding of a sustainable automotive supply chain?

19 Which department is responsible for sustainability/climate change issues?

20 Does your company have a company-wide sustainability strategy? If so, does it contain climate change mitigation related aspects?

21 In how far do you have control over climate change mitigation issues in your supply chain? 
Reasons for corporate activities

22 Do customers exercise pressure on your company regarding climate change mitigation? If yes, how?

23 Are there any legal requirements regarding climate change mitigation? If yes, which?

24 Are there any other influential stakeholders (e.g., media, NGOs, employees, banks, insurance companies)? If yes, who and how do they exercise influence?

25 Which role do economic considerations play for the implementation of sustainability/climate change mitigation activities? Have you identified any competitive advantages?

Corporate activities

26 How are sustainability/climate change mitigation aspects integrated into your supply chain management?

27 Which measures do you implement to combat climate change?

28 Do you collaborate with other supply chain actors regarding the implementation of sustainability/climate change mitigation efforts? If yes, to what extent?

29 Do you demand the implementation or compliance with sustainability standards (e.g., ISO 14001, LCA) from you suppliers?

\section{Part 3: Climate change adaptation (resilient supply chain management)}

Importance of resilience and climate change adaptation

30 What is your understanding of a resilient automotive industry?

31 What is your understanding of a resilient automotive supply chain?

32 Which risks have you identified for your company related to current/future impacts of climate change (e.g., extreme weather events)?

33 Which parts of your company (regions, departments) are especially vulnerable to impacts?

34 Who is responsible for issues related to climate change risks and adaptation? Do you differentiate between risk management and resilience management?

35 What is the importance of the following resilience-related concepts for your company and how do you deal with them? (redundancy, efficiency, agility, flexibility, and collaboration)

Reasons for corporate activities

36 Have you already been affected by climate-induced disruptions? If yes, did it lead to a change in your strategy?

37 Do customers exercise pressure on your company regarding climate change adaptation? If yes, how? 
38 Are there any legal requirements regarding climate change adaptation? If yes, which?

39 Are there any other influential stakeholders (e.g., media, NGOs, employees, banks, insurance companies)? If yes, who and how do they exercise influence?

40 Which role do economic considerations play for the implementation of sustainability/climate change adaptation activities? Have you identified any competitive advantages?

Corporate activities

41 How are resilience/climate change adaptation aspects integrated into your supply chain management?

42 Which measures do you implement to adapt to climate change?

43 Do you collaborate with other supply chain actors regarding the implementation of resilience/climate change adaptation efforts? If yes, to what extent?

44 How flexible is your collaboration with suppliers? Is it possible to change suppliers or do use multiple sourcing in order to respond to climate-induced negative impacts?

45 Are there any other „buffer resources” for such situations? If yes, which?

\section{Part 4: Overlaps and trade-offs between sustainability (mitigation) and resilience (adaptation)}

46 In how far do you see overlaps between supply chain activities related to mitigation and adaptation?

47 Which aspect is more important to you and why?

48 Have you identified any trade-offs between mitigation and adaptation activities? If yes, which? 